\title{
Integrating Chemistry: Crossing the Millennium Divide
}

\author{
Catherine E. Housecroft ${ }^{\star}$
}

\begin{abstract}
A personal account of the development of two University level chemistry books is presented. The account focuses on ways to integrate the traditional branches of chemistry into a textbook that captures the imagination of students and relates chemical principles and fundamental topics to environmental, medicinal, biological and industrial applications. The ways in which teaching methods have changed over two decades and how web-based resources can be used to improve the communication of chemical (in particular structural) concepts are highlighted.
\end{abstract}

Keywords: Chemistry textbooks · Communication · Education · General chemistry · Inorganic chemistry

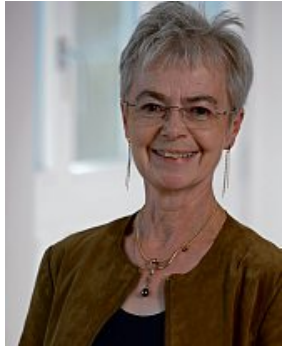

Catherine E. Housecroft is Titular Professor of Chemistry at the University of Basel. She is co-director of a highly active research group with her husband, Professor Edwin C. Constable, and has a broad range of interests spanning structural, organometallic, coordination and materials chemistries. Current research focuses on the application of coordination chemistry to sustainable energy and functional coordination polymers; she is actively involved in the Swiss Nanoscience Institute and the National Centre for Competence in Research for Molecular Systems Engineering. Current research focuses on the applications of coordination chemistry to sustainable energy (including dye-sensitized solar cells and light-emitting electrochemical cells), functional coordination polymers and the hierarchical

${ }^{\star}$ Correspondence: Prof. Dr. C. E. Housecroft Department of Chemistry

University of Basel

BPR 1096, Mattenstrasse 24a, CH-4058 Basel

E-mail: catherine.housecroft@unibas.ch assembly of surface-anchored functional molecules. She has published over 500 research papers and review articles and is also an internationally recognized author of chemistry textbooks: 'Chemistry' (coauthored with Edwin Constable) and 'Inorganic Chemistry' (originally with the late Alan Sharpe) are currently in their fourth editions. The fifth edition of 'Inorganic Chemistry' will appear in 2018, and the book has been translated into seven languages.

\section{Introduction}

Capturing the imagination of students, be they of high school age, undergraduates or at Master's level, is not always easy. Moving with the times means adapting teaching methods and continually reassessing the relevance of the taught material to the modern world. The last five decades have witnessed a revolution in the way in which we can communicate chemical concepts and facts to students. We have moved from chalk-and-talk, to the overhead projector, to computers and use of Powerpoint ${ }^{\mathrm{TM}}$ including the incorporation of movies and clips, to the use of online resources with virtual laboratory experiments. For the chemistry lecturer, the use of Powerpoint ${ }^{\mathrm{TM}}$ has great advantages for communicating complex chemical structures. On the downside, using Powerpoint $^{\mathrm{TM}}$ as a stand-alone method for delivering new material to a class of students has a tendency to result in more lecture material being crammed into the session at the expense of clarity of explanation. Coming full circle and returning to traditional chalk-and-talk methods really can have its advantages.

Where does a chemistry textbook fit into the picture? In the early 1970 s, it was common practice to expect undergraduates to purchase a number of recommended books for background reading and reference. These were usually heavy tomes, rather lacking in illustrations and the use of colour was non-existent. As the years have progressed, both the appearance and role of the textbook have changed. This article is a personal account of the conception and development of two chemistry textbooks. The first is a general chemistry text, aimed at first year university undergraduates and has developed significantly through four editions. The second text focuses on inorganic chemistry and the fifth edition will be published in 2018. Both texts have been published by the same publishing-house under various incarnations of Longman, Addison-Wesley, Pearson/Prentice Hall and Pearson Education.

\section{'Chemistry: An Integrated Approach'}

In 1991, Ed Constable (Fig. 1) and I approached Longman publishers with the idea of writing a bioinorganic chemistry text. This was very much tied to courses that we were teaching at the University of Cambridge at that time, but was not seen as an attractive project by the publisher. However, they returned to us rather quickly with the idea of a general chemistry text specifically aimed at the non-US market. We accepted this challenge. During our careers to that point, we had often seen the same material taught in a single chemistry course to the same group of students by members of inorganic, organic and physical divisions using different conventions and notations. To the first year student in particular, this is confusing to say the least. We developed a plan for a book entitled 'Chemistry: An Integrated Approach' which would weave the threads of traditional branches of chemistry together and would also link the subject to the everyday lives of the students reading the text (Fig. 


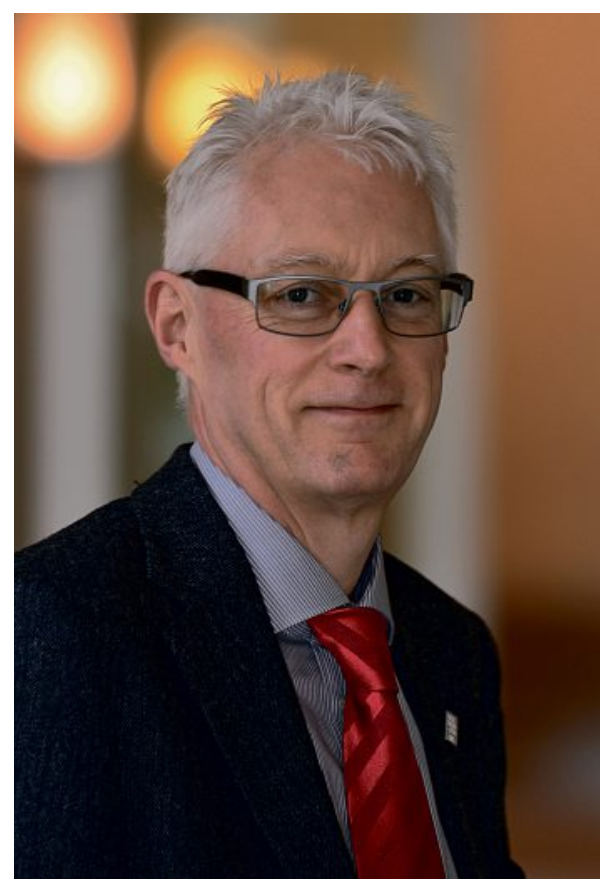

Fig. 1. Edwin C. Constable: co-author of 'Chemistry: An Integrated Approach'.

2). We started work on the project just after moving from Cambridge to Basel in 1993. The text was four years in the making and we agonized, first, over the order of the topics and, second, over the level of mathematics that we could assume for a first year science student. We decided to take a very low-key approach to the derivation of mathematical equations, taking the view that (for first year students) it was more important to know how to apply an equation (e.g. in thermodynamics or kinetics) than to be able to derive the equation from first principles. Topic order caused us considerable concern and endless discussion, and we eventually decided to follow an unconventional path. We made an assumption (in hindsight, the chemistry community was not ready for this) that a first year chemistry course could (and would) be taught by one person, and we developed a chapter order that alternated physical, organic and inorganic topics to provide a logical structure that we felt justified the book's title. In order to make the book attractive to students and lecturers alike, we introduced topic 'boxes' to connect chemistry to real life. Themes within an undergraduate chemistry course are easily related to the lives of students through environmental, medicinal, biological, industrial and other issues, and a side track into "why is this useful and important to us in everyday living" can lift even the driest of topics to a new level. 'Chemistry: An Integrated Approach' also made extensive use of fully worked examples of calculations, especially in the physical chemistry chapters. As a child, I had been brought up with the message: "If at first you don't succeed, try, try again". So it is with chemistry calculations: students require inexhaustible supplies of questions (and answers) to build up knowledge and confidence. To accompany the textbook, we devised a 'Self-Study Workbook' (Fig. 3) containing exercises and explanations of how to tackle them. A hard copy workbook was, in 1997 when 'Chemistry: An Integrated Approach' was published, distinct from the more usual Solutions Manuals that accompanied many US general chemistry texts. Later we would abandon this for more focused multiple-choice quizzes.

The project was not without its frustrations. Given that (in 1993) so many US general chemistry texts were produced in full colour, we argued that, even for a non-US market, 'Chemistry: An Integrated Approach' would only be successful if we could enliven the subject with the use of colour and photographs. However, levels of investment by publishers are difficult to change, and since Longman was working with an untested text, we were allowed only 'one colour'. In practice, this meant shades of red could be incorporated into the text design. This was not very attractive, but was a step up from monochrome production. After much discussion, the publisher allowed us four 'glossy pages' (to be placed together at the beginning of the book) in which to accommodate nine colour photographs. Another difficulty was artwork delivery. It was not until the next edition of the book that I was able to generate most of the artwork in final graphic-file form myself. For the first edition, most graphics for the figures in the book were redrawn by a graphics artist with no

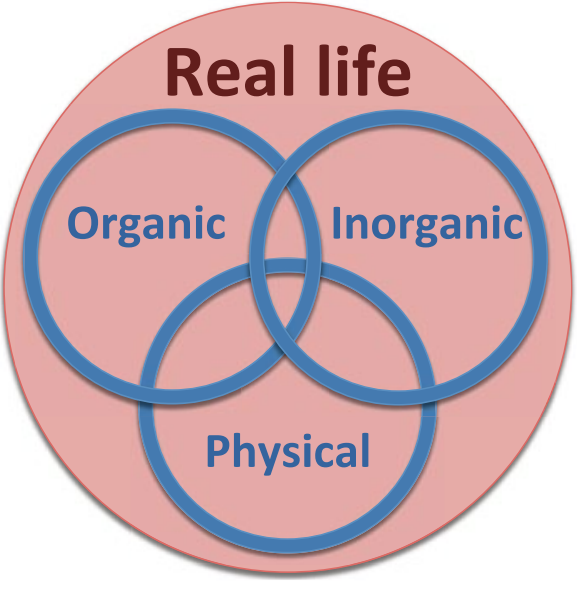

Fig. 2. The concept of integrated chemistry.

scientific background. With tremendous support from Longman, 'Chemistry: An Integrated Approach' was published in $1997^{[1]}$ and spawned translations in Italian and Russian.

\section{'Chemistry: An Integrated Approach' becomes 'Chemistry'}

As part of the commissioning process for the second edition of the text, the publisher carried out market research to discover which aspects of the first edition were deemed successful and which not. This is the kind of activity that results in a mountain of completed questionnaires with many personal statements which contradict one another. The underlying feedback about our integrated approach to firstyear teaching was disappointing and typical comments were that we should separate physical, inorganic and organic chemistry

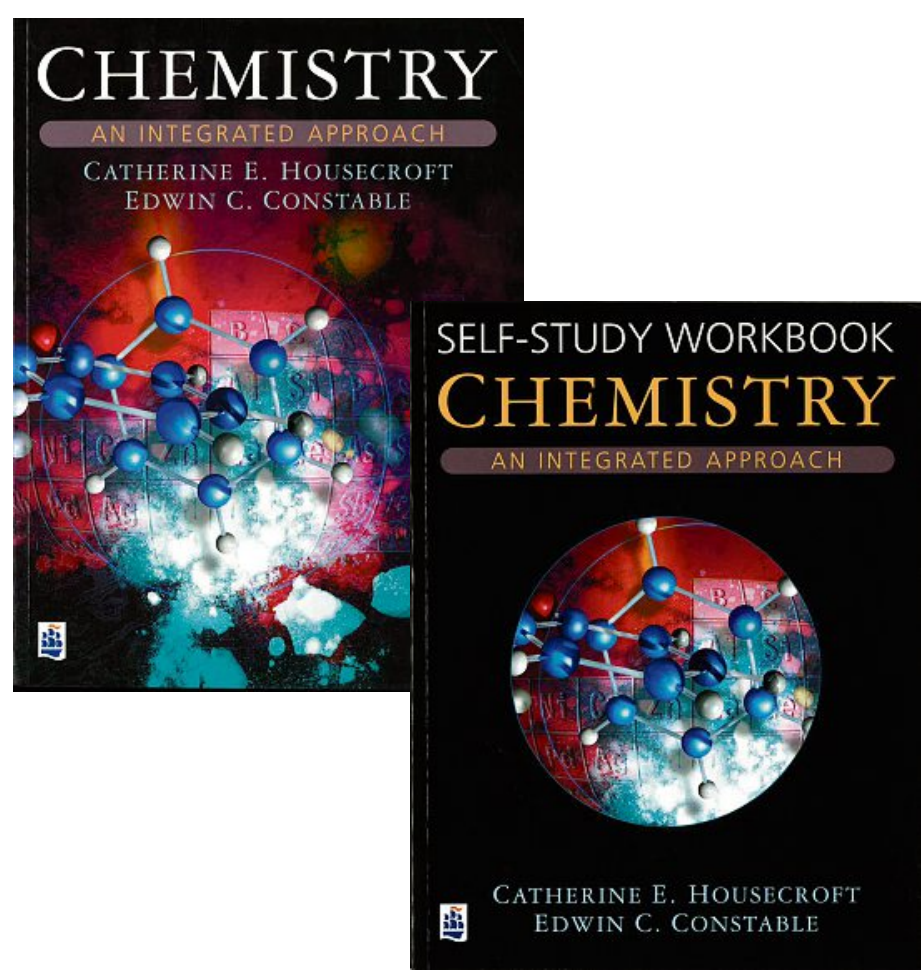

Fig. 3. The first edition of 'Chemistry: An Integrated Approach' was published in 1997 with an accompanying 'SelfStudy Workbook'. Reproduced with permission: 'Chemistry: An Integrated Approach', C. E. Housecroft and E. C. Constable, Pearson Education Limited, Addison Wesley Longman Limited 1997; 'SelfStudy Workbook', C. E. Housecroft and E. C. Constable, Pearson Education Limited, Addison Wesley Longman Limited 1997. 
into clearly defined sections and that it was not realistic to expect one lecturer to be willing or able to teach all aspects of a first year course. While our opinion was that the university and college community was missing an opportunity to radically alter its way of presenting first year chemistry, our arms were twisted by the publisher. The second edition would only be commissioned if we reorganized the presentation of topics. However, our inner feelings came through in the preface where we wrote: "The first edition strove to present a text in which the barriers between physical, organic and inorganic chemistries were broken down ... we recognize that old habits die hard and there is still an apparent need for traditional areas of chemistry to be recognizable." Thus, the decision to regroup chapters "is in response to the market and has not been taken lightly". The sweetener was that we could move to a full-colour text, albeit with a rather limited budget for colour photographs. A great step forward was that the era of the internet was upon us and this gave us the chance to make a downloadable 'Solutions Manual' available, and to provide test-banks of self-testing multiple choice questions, an innovation that we have developed significantly over the four editions of the book. We were also able to make two-dimensional illustrations of molecular structure from the hard-copy book come alive by letting students (and lecturers) view them as three-dimensional, rotatable structures. The worries we had about mathematics were finally solved (in part) by writing of an accompanying 'Mathematics Tutor' which was available via the internet.

In addition to reordering chapters, we responded to the market by increasing the depth of coverage of physical chemistry topics and expanded the topics covered within organic chemistry. It is always the case, that on going from one edition to another, the market calls for more material and never less, thus making the task of the author increasingly difficult. In order to retain an integrated feel to the book which would enable students to understand that physical, inorganic and organic chemistries are not stand-along disciplines, we introduced substantial cross-referencing. We also further developed the use of topic boxes to real-life applications to link different branches of chemistry. The second edition of 'Chemistry' (an integrated approach being dropped) was published in 2002 (Fig. 4). [2]

Commissioning of a third edition of 'Chemistry' came only two years after publication of the second edition. The second edition of 'Chemistry' was aimed very much at the UK market where the book was used widely for first year teaching including foundation courses to bridge

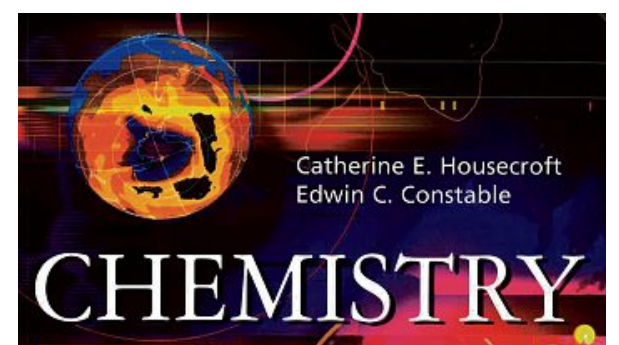

pains to generate all the material that accompanied the book. We felt that this was the best strategy for ensuring consistency and quality. However, we were coming under increasing pressure from the publisher to link the book to other banks of questions that were associated with other Pearson products.

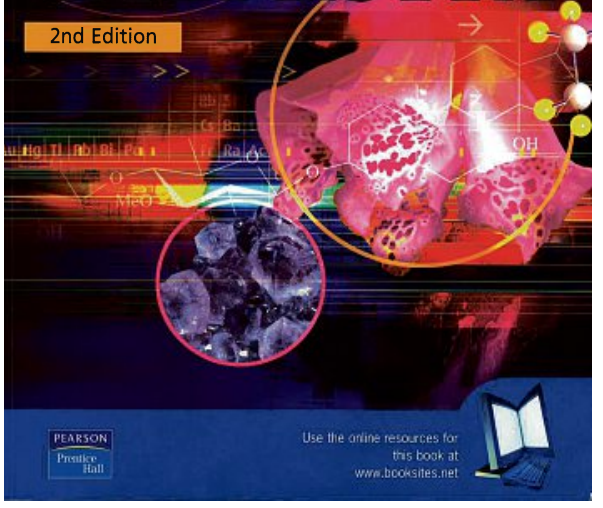

Despite being forced away from a truly integrated approach, our strategies for developing the book through the second and third editions made the text successful at an international level. We had reached a satisfactory balance between rigour, chemical content and well-illustrated examples of applications, environmental issues and chemistry in the natural world. And so to the fourth edition. As anticipated, the market requested further expansion of the text and demanded more bio-organic content and the fundamentals of more analytical techniques. The former was readily satis-

Fig. 4. The second edition of 'Chemistry' was published in 2002 and was supported by an online website. Reproduced with permission: 'Chemistry: An Introduction to Organic, Inorganic, and Physical Chemistry', 2nd Edn, C. E. Housecroft and E. C. Constable, Pearson Education Limited, 1997, 2002.

the high-school/university divide. Our next goal was to reach a wider, international audience. It was never our intention to compete in the US market. The starting level of material in 'Chemistry' did not mesh with US Freshman Chemistry courses, and anyway, this market is saturated with many excellent general chemistry texts. However, feedback from international colleagues in countries other than the US encouraged us to develop the book to meet their needs. This required a rewrite of the initial chapters on fundamental principles to include more basic topics with many more worked examples of calculations (masses and moles, concentrations of solutions, reaction stoichiometry and balancing equations), all supported by increased numbers of multiple choice questions on the accompanying website. On going to the third edition, ${ }^{[3]}$ we addressed an increase in the number of students in the biosciences using 'Chemistry' by introducing more examples of biological relevance, augmented with new boxes focused on the environment and biology. The book grew from 1158 to 1285 pages and the third edition was published in 2006. The companion website was also evolving and now provided lecturers with an Instructor's Manual and Powerpoint ${ }^{\mathrm{TM}}$ slides of all figures and tables in the book. The multiple choice questions for students were now linked to profile tools that allowed the results of an online quiz to be sent by email to the instructor. Although there was an increasing amount of supporting material, Ed Constable and I were at fied by increased coverage of mono-, diand polysaccharides, lipids and proteins and the inclusion of many more examples of bioscientific and pharmaceutical relevance. The latter was more difficult. My first attempt at a chapter entitled 'Analytical techniques' resulted in "mind-numbingly boring reading", according to my co-author (and husband). A rethink was in order, and we came up with the idea of using case studies based on media reports to demonstrate the use and importance of analytical methods. Thus, a 2007 news headline about pet food contamination provided a case study for LC-MS. The opportunities that this media story concerning melamine and cyanuric acid included a review of tautomers and hydrogen bonding, the principles of the LC instrument and its interface to MS, a review mass spectrometry, calibration, the use of standards, and detection limits. The chapter was retitled 'Chemistry in the Workplace' which is surely more appealing than 'Analytical techniques'.

We had designed 'Chemistry' to be a text with dual use. On the one hand, courses could be structured around the chapters and problems from the book or accompanying website could be specifically set as support material for classes. On the other hand, not all instructors use a text in this way, and the wide use of worked examples combined with extensive end-of-chapter problems make 'Chemistry' amenable for individual student use. The more problems that a student tackles, the stronger the confidence level. Throughout the four editions, we gradually extended and improved the end-of-chapter problems. In addition to problems on narrow topics mapping onto the chapter material, we included (from the second edition onwards) a set of 'additional problems'. Each of these problems draws on a breadth of knowledge and pulls topics together, thereby cajoling students 
into the wider picture of the subject. In the fourth edition, we introduced a set of problems at the end of each chapter called 'Chemistry in daily use'. This was devised to demonstrate how the chapter material might be relevant to our everyday lives, industry, commerce, forensics, medicine and the environment.

The visual appeal of a textbook is highly important to students. There needs to be a desire to open a book and read it. Compared to the earlier editions, the fourth edition contained many more colour graphics and photographs. When teaching (at whatever level), both Ed Constable and I enjoy showing students photographs (or drawings if necessary) of 'names' - take the Grignard reagent, for example. Who was Grignard? What did he look like? Indeed, was Grignard a 'he' or a 'she'? In what time period did he live? In the fourth edition of 'Chemistry', we wanted to include as many photographs of 'names' as we could. But this was a topic for debate with our colleagues at Pearson who saw this material as dry and uninformative. However, we persevered and were finally able to illustrate many eminent chemists, thus making students more aware of the development of the subject through the last couple of centuries.

The fourth edition of 'Chemistry' appeared in 2010 (Fig. 5). [4] Just as the internet had had an impact of the second edition, the advent of e-books and e-publishing meant that the now hefty tome (1517 pages) was electronically accessible. The book was also tied to an online Pearson product called Mastering Chemistry. Although this had been developed independently from our text, it did provide a supportive chemistry homework and tutorial package.

Twenty-four years after we sat with blank paper and scribbled some ideas for a plan for 'Chemistry: An Integrated Text', we have seen development, not only of the book itself, but of the supporting material available for instructors and for students. However, if we were able to independently choose a direction for a new edition (or a new general chemistry text), we would opt for the integrated approach once again. Only with this strategy can undergraduate students appreciate how the branches of chemistry interconnect. In our opinion, a more rounded view of the subject equips a first year student more adequately for a career, not only in chemistry, but in biosciences, nanosciences, physics, medical sciences or in another discipline.

\section{'Inorganic Chemistry'}

Not long after work on 'Chemistry: An Integrated Text' began, Longman approached me about a second project. This was to co-author a fourth edition of Alan Sharpe's 'Inorganic Chemistry'.
The world is a small place. When Alan Sharpe (Fig. 6) retired in 1982 from the Department of Chemistry, University of Cambridge, his replacement was Ed Constable. Moreover, Sharpe's 'Inorganic Chemistry' had its origins in 'Modern Aspects of Inorganic Chemistry' by Harry Emeléus and Alan Sharpe, the fourth edition of which was published in 1973. ${ }^{[5]}$ The small-world scenario goes further - Harry Emeléus was my academic great-grandfather ('Urgrossdoktorvater'), and Harry Emeléus and Ed Constable both attended Hastings Grammar School in the UK, albeit it decades apart. I agreed to take on the challenge, but we soon realized that the book needed such a complete rewrite to bring it up to date, with major changes to content, pedagogical features and illustrations, that we should start afresh. Writing of the first edition of Housecroft and Sharpe's 'Inorganic Chemistry' began in 1997. There were a few minor hurdles to overcome. Throughout our collaboration which spanned eleven years, Alan and I met only once. With modern communication networks, contact and exchange of manuscripts between colleagues in Basel and Cambridge is deemed routine. However, Alan neither used (nor would start to use) a computer and neither did he enjoy telephone calls, saying that he needed time to think. Use of a Fax machine was also not the norm for him, and so we agreed to work entirely using the postal system, with me sending him manuscript drafts and he correcting and providing suggestions longhand. Amazingly, this worked. As a consequence of our age difference and backgrounds, we approached inorganic chemistry very differently and the teamwork brought critical argument to many concepts that was not possible for either one of us alone.

In the preface to the third edition of Sharpe's 'Inorganic Chemistry', ${ }^{[6]}$ he wrote that the book featured "an emphasis on thermodynamics and a somewhat sceptical attitude towards simple valence theories". In planning the new text, we retained the general structure of chapters dealing with physical inorganic chemistry followed by descriptive chemistry. After much discussion, Alan agreed that we should significantly expand the treatment and applications of molecular orbital theory. In the preface to the first edition of 'Inorganic Chemistry', we wrote that our aim was "not only of introducing the topic (of MO theory) but also showing how an objective, and cautious, approach can provide insight into particular bonding features of molecular species". This approach satisfied both authors, although in later editions we would have to expand the use of group theory to satisfy the market needs. Greater emphasis was placed on the

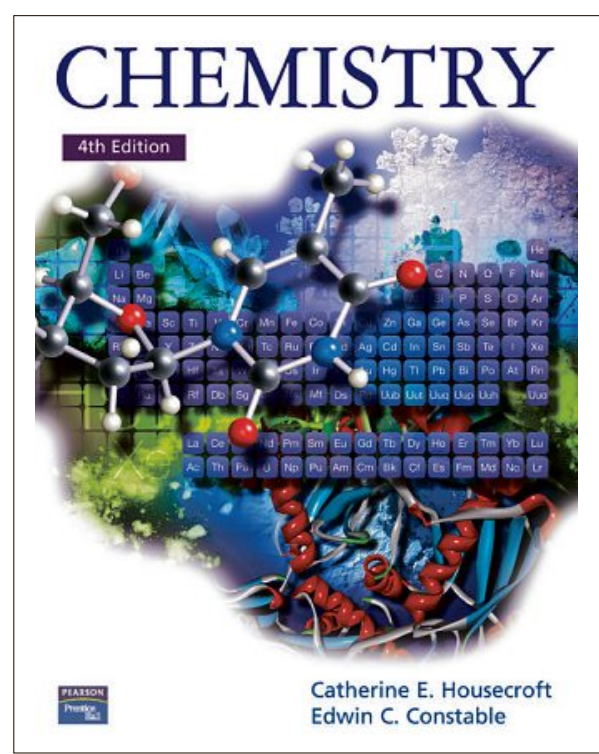

Fig. 5. The fourth edition of 'Chemistry' (2010) is supported by an online website and is linked to an online tutorial and homework site. Reproduced with permission: 'Chemistry', $4^{\text {th }}$ Edn, C. E. Housecroft and E. C. Constable, Pearson Education Limited, 1997, 2010.

use of modern spectroscopic methods, in particular multinuclear NMR spectroscopy, and the new text featured four 'special topic' chapters covering inorganic kinetics, catalysis, solid-state chemistry and bioinorganic chemistry. Sharpe's 'Inorganic Chemistry' was a very traditional text, with relatively few illustrations. In order to grasp the attention of students and lecturers alike, we replicated some of the didactic features developed for Housecroft and Constable's 'Chemistry'. Every chapter featured worked examples, not only of calculations but also of data analysis and explanations of trends in observed structural and experimental properties. To boost student confidence, we added sets of 'self-study exercises' after the worked

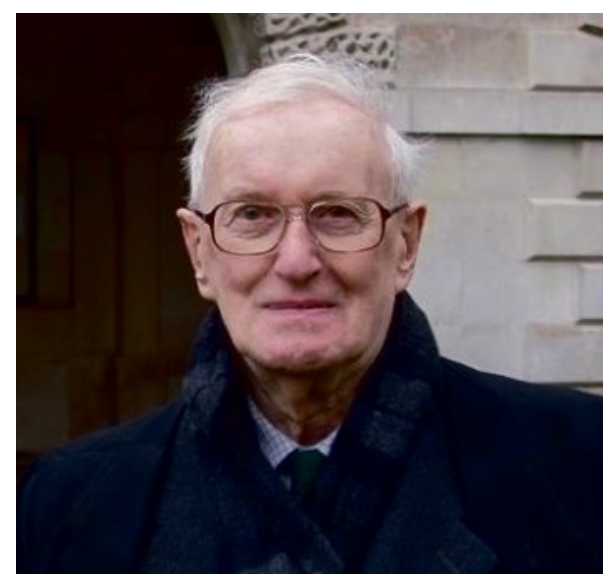

Fig. 6. Alan G. Sharpe (1921-2008). The photograph was taken in 2005 by Dr. Timothy Sharpe, grandson of Alan who is now, coincidentally, working in the Biozentrum in the University of Basel. 
examples, each set being closely tied to the worked example. Extensive sets of end-of-chapter problems were provided and (unlike the previous books from Alan Sharpe), we supplemented the main text with a hard-copy 'Solutions Manual'. An important aspect of the book was that we chose many examples from the recent literature, and this has remained central to the development of the later editions. The publisher's budget for the project allowed us use of one colour (this time blue) and, although not ideal, did enhance the presentation of graphics. The support of the publisher's production team pushed us forward to final publication in 2001. We felt that we had achieved a new-style inorganic chemistry text which combined Alan Sharpe's fondness for inorganic thermodynamics and solution chemistry with modern uses of bonding theories and spectroscopic methods. The descriptive chemistry was organized by group (1,2 and 1318 ) or periodic block ( $d$ and $f$ elements) and, although detailed, was not simply a reference manual. When I am teaching descriptive inorganic chemistry, I am always keen that students know the sources of elements, the ease or difficulties of extracting them, and are aware of their sustainability. We built this knowledge into the book in topic boxes with relevant statistics, and also incorporated discussions of the applications of inorganic chemicals and their impact on the environment. The timing was right for the inclusion of a companion website through which lecturers could access supplementary material for teaching, and students could have open access to multiple choice questions (self-testing) and rotatable structures of molecules featured in figures in the text.

The first edition of 'Inorganic Chemistry' ${ }^{[7]}$ proved to be a popular, international text, so much so that Pearson was keen to commission a new edition with a publication date of 2005, Gratifyingly, Pearson was also prepared to invest in a full-colour production. In pedagogic terms, this allowed us to enhance the presentations of molecular structures and three-dimensional images. Use of distinguishing colours for specific features (worked examples, self-study exercises, boxed material on theoretical background, resources and the environment, or applications) made the book easier for students to use. With the commissioning of the book came the usual round of questionnaires answered both by adopters and non-adopters of the book. Feedback told us that the market wanted an expansion of the book (ultimately this would be from 808 to 949 pages) with many more selfstudy exercises that would make stronger connections between descriptive chemistry and fundamental principles. The call for more group theory and applications of molecular orbital theory did not go down well with my co-author. However, it is a fact that the market is critical in dictating how a text-book develops and we responded with significant changes to the chapters on molecular symmetry and bonding. We commented in the preface: "we do not feel that a book, the prime purpose of which is to bring chemistry to a student audience, should evolve into a theoretical text". Nonetheless, future editions of the book would have to adapt to the continued demands for applications of group theory. On going from the first to second edition, we added to the descriptive chemistry with examples from the current literature, thus keeping the book as up to date as possible. Two of the chapters that required significant updating on going from one edition to the next of 'Inorganic Chemistry' were those on solid-state chemistry and bioinorganic chemistry. Major changes would come in later editions, but for the second edition a key advance to bring to the attention of readers was the discovery of a central, 6-coordinate atom at the centre of the FeMo-cofactor in nitrogenase. This has been a story that has been unravelling through the last decade and each edition of the book tells a different and updated story.

The second edition of 'Inorganic Chemistry' (Fig. 7) ${ }^{[8]}$ was accompanied by a hard copy 'Solutions Manual' (essential for the US market in particular) and online resources which provided students with a self-grading multiple choice test bank and rotatable three-dimensional models of the molecular structures represented in two dimensions in the text. Providing Powerpoint ${ }^{\mathrm{TM}}$ slides of figures and tables for lecturers via the online site was a new innovation for the book, and proved popular. By 2005, both Housecroft and Sharpe's 'Inorganic Chemistry' and Housecroft and Constable's 'Chemistry' were benefitting from additional material supplied to instructors via the accompanying online sites. However, it is interesting to note that students did not (and, in 2017, still do not) appear to make optimal use of the graphics interface available online. This is a pity, because thinking in three-dimensions is often difficult for undergraduates and making the transition from a two-dimensional figure on a page to a three-dimensional structure is extremely advantageous.

The content, structure and didactics of 'Inorganic Chemistry' continued to be as popular as ever with teachers and students, and we were pleased to see the book widely adopted internationally with a German translation of the second edition appearing in 2006. Keeping a book up to date requires continual perusal of the literature and maintaining an 'ideas file' for future editions. With the publication of
Housecroft and Constable's 'Chemistry' in 2006, I was (apparently) in need of a new project and the publisher considered it time to start to think about a new edition of 'Inorganic Chemistry'. It takes time to commission an edition, and I already had some ideas for reorganizing the text. It had always annoyed me that the chapter numbers corresponding to the descriptive main group chemistry were displaced from the relevant periodic group number by one. This may seem a trivial point, but would it not be more logical (and easier) for students to find the discussion of group 15 in Chapter 15 instead of Chapter 14? Since the customary questionnaires at the commissioning stage fed back a message that students needed expanded coverage on fundamental concepts, we decided to split Chapter 1 (Basic concepts) into two chapters (Basic concepts: atoms and Basic concepts: molecules). This had the desired effect of making Chapter 10 'Hydrogen', Chapter 11 'Group 1', Chapter 12 'Group 2', Chapter 13 'Group 13' and so on. Feedback from the questionnaires indicated that the expansion of the discussions of MO theory and group theory on going from the first to second editions had been well received, but remained inadequate. In response, we further developed the use of character tables to determine symmetry labels of vibrational modes, and improved the discussion of term symbols and microstates in the discussions of electronic spectroscopy. The third edition of 'Inorganic Chemistry' contained many more selfstudy exercises; the audience could never have enough practice in problem solving.

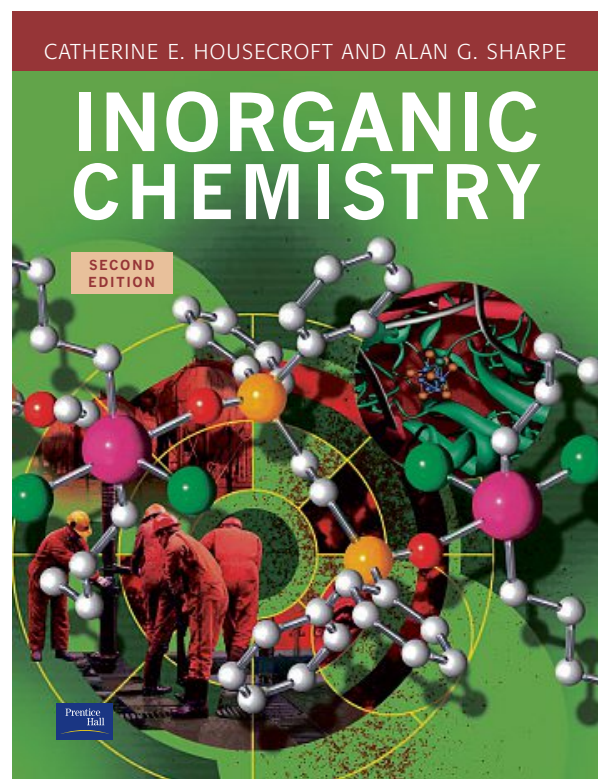

Fig. 7. The second edition of 'Inorganic Chemistry' was published in 2005. Reproduced with permission: 'Inorganic Chemistry', $2^{\text {nd }}$ Edn, C. E. Housecroft and A. G. Sharpe, Pearson Education Limited, 2001, 2005. 
The earlier editions of the text provided significant coverage and examples of multinuclear NMR spectroscopy applied to inorganic compounds. In the third edition, we introduced the reader to a wider range of experimental techniques, and this (largely) boxed material would be further developed in later editions.

For the third edition of 'Inorganic Chemistry', the publisher agreed for a photograph-budget, allowing a significant number of the topic boxes dealing with commercial applications, environmental issues and biological/medicinal applications to be illustrated. This had an impact on the visual appeal of the text, engaging students in what could otherwise be rather dry reading. The third edition was published in 2008, ${ }^{[9]}$ and not long after, Alan Sharpe passed away at the age of 86 . He had been an extremely thought-provoking colleague to work alongside, and his long-held belief that thermodynamics is at the heart of inorganic chemistry lives on in the text as it enters its fifth edition in 2018.

By 2010, Pearson was once again asking for a new edition. It was important that the book retained its brand as Housecroft and Sharpe's 'Inorganic Chemistry' even though I was now working alone on the revisions. I was (and remain) greatly indebted to Ed Constable for his willingness to act as a sounding board for ideas and for checking newly set problems. When a student reads a self-study exercise or end-of-chapter problem, it is essential that the phrasing of the question has only one meaning, and four eyes are better than two eyes for recognizing ambiguities. As was always the case, the commissioning questionnaires asked for expansions of a number of topics and features, but with the third edition having reached 1098 pages, there was a limit to further expansion. The boxed material on experimental methods in the third edition had been well received, but there were numerous requests for it to be combined into a new chapter. After discussions with a number of colleagues, I took the decision that the time was right to remove the half-chapter that was devoted to nuclear chemistry, making space for a chapter dealing with modern experimental techniques: purification methods, elemental analysis, thermogravimetric analysis, mass spectrometry, vibrational, electronic, NMR, EPR, Mössbauer and photoelectron spectroscopies, diffraction methods and computational methods. Alan Sharpe would have been very sceptical of this last section, but the widespread use of molecular mechanics and DFT calculations deemed some mention necessary. Nuclear chemistry did not entirely disappear from the text; decay chains now appeared within the discussion of actinoid metals.
On going from the third to fourth editions, the market demanded even more worked examples and self-study exercises. I decided to base more of these on literature examples, introducing more citations into the book in the hope of encouraging students to make forays into the research literature. I consider that the development of the book through its various editions benefits from the fact that I am also highly active in research. Being aware of cutting-edge research areas significantly influences choices of examples in the text, and also affects the decisions made in what new material should be introduced. An innovation for the fourth edition was the introduction of a set of end-of-chapter problems called 'Inorganic chemistry matters'. The basis for each problem was to link material from the chapter to an everyday application or a topical research issue, something that helps students grasp the significance of even the most theoretical of topics.

In addition to the regular updates of examples in the descriptive chemistry chapters, it was timely for the fourth edition to rewrite the chapter dealing with solid-state chemistry. In the first three editions of 'Inorganic Chemistry', this had been entitled 'Some aspects of solid state chemistry'. With the award in 2010 of the Nobel Prize in Physics to Geim and Novoselov for "groundbreaking experiments regarding the two-dimensional material graphene", it was time to change the emphasis of the chapter to 'Inorganic materials and nanotechnology'. The chapter was expanded to encompass transparent conducting oxides and their applications in devices (dye-sensitized solar cells, organic light-emitting diodes and light-emitting electrochemical cells) and a wider coverage of superconductors, and a section on graphene was added to complement the discussion of carbon nanotubes and carbon fibres.

With a publication date of $2012,{ }^{[10]}$ the book needed to have more modern feel (Fig. 8). The basic page designs of the second and third editions had been similar and were beginning to look dated. The design team at Pearson worked with me to produce innovative opening panels for each chapter in the fourth edition. The design was based upon one we had developed for the fourth edition of 'Chemistry' and combined molecular graphics with the photographic skills of Ed Constable. The topic boxes in the book were enhanced further by the publisher supporting a budget for an increased number of colour photographs. The main text was accompanied by an updated 'Solutions Manual' and increased online resources.

One aspect of updating 'Inorganic Chemistry' that I have failed to mention so far is the impact of the IUPAC. As far as possible, each edition has incorporated the latest IUPAC nomenclature recommendations. This is, however, not always a smooth course. On going from the first to second edition, we followed IUPAC recommendations and changed 'bidentate' to 'didentate' throughout the book. However, a major overhaul of inorganic nomenclature in 2005 resulted in a reversal of the earlier bi- to di- change, and the third edition of 'Inorganic Chemistry' found us back once again with bidentate. From the third edition onwards, obsolete names such as tetrahydroborate and hexafluorophosphate were replaced (e.g. tetrahydridoborate and hexafluoridophosphate). This change originates in the fundamental change of fluoro, chloro, bromo etc. to fluorido, chlorido, bromido etc. coordinated ligands. ${ }^{[11]}$ Input from colleagues within the IUPAC (Neil Connelly, Jan Reedijk and Alan Hutton) has greatly assisted me in maintaining an updated text for each new edition.

In 2015, I discussed with Pearson the idea of an electronic and interactive edition of 'Inorganic Chemistry'. They were keen to develop an electronic product with active links and I felt this would be extremely attractive to students. Despite initially being positive about the concept, it was eventually put on the back-burner and instead, Pearson commissioned the fifth edition as a hard-copy text. The main aim of this revision has been to generally update the text rather than make radical changes. When I started working with Alan Sharpe in 1997, it was possible for us to manually search the high-impact chemistry journals

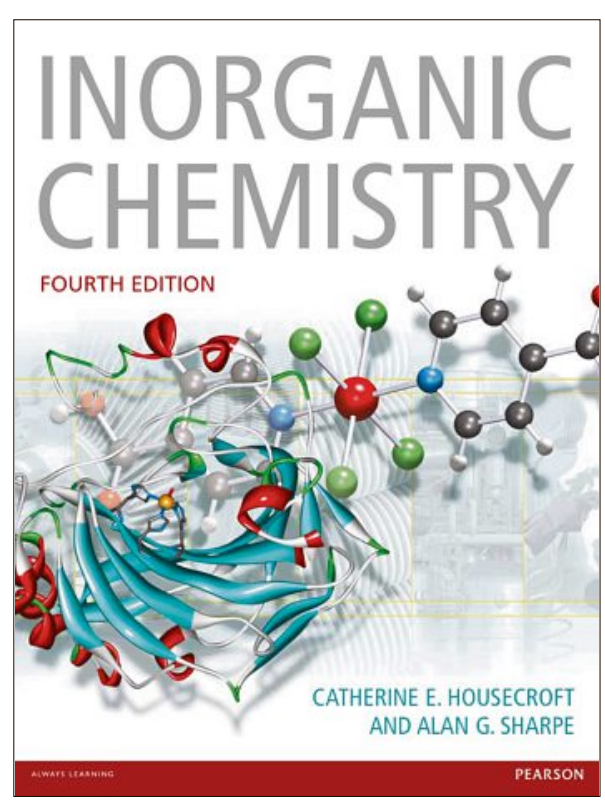

Fig. 8. The fourth edition of 'Inorganic Chemistry' (2012) had a fresh design and modern feel. Reporduced with permission: 'Inorganic Chemistry', 4th Edn., C. E. Housecroft and A. G. Sharpe, Pearson Education Limited, 2001, 2012. 
and to select examples and advances to include in the text. Now, the sheer number of publications in an ever-expanding range of journals covering inorganic chemistry, physical sciences, nanotechnology, bioinorganic, environmental sciences etc. makes it impossible to incorporate all significant developments. In order to compensate for this problem, more literature citations have been incorporated as footnotes and I hope that this will assist lecturers in finding new and exciting examples to present during class. When the fifth edition is published in 2018, readers will notice that the periodic table has been extended to the element with atomic number 118 . In December 2016, the IUPAC published the accepted names for elements 113 (nihonium), 115 (moscovium), 117 (tennessine ) and 118 (oganesson). While there is little chemistry that can be discussed about the 'super-heavy' elements, the symbols Nh, $\mathrm{Fl}, \mathrm{Mc}, \mathrm{Lv}$, Ts and $\mathrm{Og}$ will become familiar to students.

The Kapustinskii equation has been used since $1956^{[12]}$ to estimate lattice energies of ionic compounds. While this remains useful, it is a gross approximation. In 1999, Jenkins et al. proposed an alternative approach which relates the lattice energy to the inverse cube root of the volume of the formula unit of an ionic compound.[13] Since its introduction, this volume-based thermodynamic (VBT) approach to lattice energies has gained significant attention in the literature and has recently been applied to estimate hydration enthalpies. ${ }^{[14]}$ The VBT approach has been introduced into the fifth edition of 'Inorganic Chemistry'. Starting from crystallographic ion-volume data, the VBT method affords a straightfor- ward means by which students can use to gain insight into the thermodynamic stability of a new material. The strengthening of inorganic thermodynamics within the fifth edition of 'Inorganic Chemistry' is certainly something of which Alan Sharpe would have approved.

'Inorganic Chemistry' is a leading international text and has been translated into seven languages (German, French, Spanish, Portuguese, Japanese, Greek and Czech). Since production of a translated text is a major task, each is a version of the book frozen in time and the older translations (German and French, for example) lack some of the innovative ideas for teaching that appear in the later editions. This is a pity, because the text has developed significantly from the first to fifth editions, not only in content but in the inclusion of ever increasing numbers of self-study exercises to forge stronger links between principles and descriptive chemistry. This is particularly true for the $d$-block where crystal-field theory, magnetic properties and electronic spectroscopy are often taught separately from descriptive coordination and solid-state $d$-block metal chemistry. I hear from many colleagues and students that one of the reasons that they like Housecroft and Sharpe's 'Inorganic Chemistry' is the way that the authors have endeavoured to show the relevance of the subject to the world in general, and to connect theory and real chemistry. This has all the hallmarks of integration, and so we come full circle to Ed Constable's and my desire to teach first year chemistry in an integrated fashion.

Received: September 29, 2017
[1] C. E. Housecroft, E. C. Constable, 'Chemistry: An Integrated Approach', Addison Wesley Longman, Harlow, 1997.

[2] C. E. Housecroft, E. C. Constable, 'Chemistry', 2nd Edn, Prentice Hall, Harlow, 2002.

[3] C. E. Housecroft, E. C. Constable, 'Chemistry', 3rd Edn, Prentice Hall, Harlow, 2006.

[4] C. E. Housecroft, E. C. Constable, 'Chemistry', 4th Edn, Prentice Hall, Harlow, 2010.

[5] H. J. Emeléus, A. G. Sharpe, 'Modern Aspects of Inorganic Chemistry', 4th Edn, Wiley, New York, 1973

[6] A. G. Sharpe, 'Inorganic Chemistry', 3rd Edn, Longman, Harlow, 1992.

[7] C. E. Housecroft, A. G. Sharpe, 'Inorganic Chemistry', Prentice Hall, Harlow, 2001.

[8] C. E. Housecroft, A. G. Sharpe, 'Inorganic Chemistry', 2nd Edn, Pearson Education, Harlow, 2005.

[9] C. E. Housecroft, A. G. Sharpe, 'Inorganic Chemistry', 3rd Edn, Pearson Education, Harlow, 2008.

[10] C. E. Housecroft, A. G. Sharpe, 'Inorganic Chemistry', 4th Edn, Pearson Education, Harlow, 2012.

[11] 'Nomenclature of Inorganic Chemistry: IUPAC Recommendations 2005, Eds N. G. Connelly, T. Damhusm R. M. Hartshorn, A. T. Hutton, RSC Publishing, Cambridge, 2005.

[12] A. F. Kapustinskii, Quart. Rev. 1956, 10, 283.

[13] H. D. B. Jenkins, H. K. Roobottom, J. P. Passmore, L. Glasser, Inorg. Chem. 1999, 38, 3609.

[14] C. E. Housecroft, H. D. B. Jenkins, RSC Adv. 2017, 7, 27881. 